\title{
Effective Microbial Consortium of Bacteria Isolated from Hydrocarbon Polluted Soils of Gujarat, India
}

\author{
Mandalaywala HP, Ratna Trivedi* \\ Department of Environmental Sciences, Shree Ramkrishna Institute of Computer Education \& Applied Sciences \\ M.T.B. college campus, Athwalines, Surat-395001, Gujarat, India
}

Received: February 03, 2016; Accepted: April 14, 2016; Published: April 20, 2016

*Corresponding author: Ratna Trivedi, Department of Environmental Sciences, Shree Ramkrishna Institute of Computer Education \& Applied Sciences, M.T.B. College campus, Athwalines, Surat-395001,Gujarat, India.E-mail: mandalaywalahetal@gmail.com;drratnatrivedi@gmail.com

\begin{abstract}
Hydrocarbons are widely distributed in environment owing to its extensive use as pesticides, petroleum products or other organic compounds. Hydrocarbons being mutagenic and carcinogenic in nature, it has led to various serious threats to living form. Pollution can ensue due to accidental spillage or leakages while handling and transportation of such compounds. Thus it becomes necessary to ensure safe removal and disposal of pollutants, to avoid further dispersal in different environmental layers. Bioremediation is one such effective treatment methods which render the pollutants harmless. Thus studying hydrocarbon utilizing bacteria becomes an essential step to formulate an effective bioremediation process. Hydrocarbon utilizing bacteria were isolated from a hydrocarbon based polluted site and scrutinized by series of tests. Among the isolates, five Pseudomonas species have been found to be effective in hydrocarbon utilizing capability. The isolates were identified using 16 sRNA sequencing procedure.
\end{abstract}

Keywords: Hydrocarbons; Hydrocarbon utilizing bacteria; Effective microbial consortium; 16s rRNA sequence

\section{Introduction}

Microorganisms play a vital role in maintaining a healthy ecological balance. Their ability to transform and degrading many types of pollutants have been widely recognized [1]. Several microorganisms may be involved in the reactions of biogeochemical cycles and in some cases they are the only living forms that are capable of degrading the complex elements of nature and regenerating a form that can be consumed by other organisms [2]. Hydrocarbons are organic compounds that lack functional groups and thus make it a polar. They are chemically less reactive at room temperature [3]; and insoluble in water. In this study petroleum derivatives are taken into consideration as hydrocarbon source. Various community play vital role in degradation of hydrocarbon. Petroleum is a heterogeneous mixture of hydrocarbons including aliphatic, alicyclic and aromatic in varying concentration depending upon the origin and nature. Henceforth, hydrocarbons term is used in general for the ease of discussion here. Hydrocarbons differ in their susceptibility to the microbial degradation, and are in general ranked as follows:
Linear alkanes $>$ branched alkanes $>$ small aromatics $>$ cyclic alkanes i.e., the simpler the structure, more the susceptibility to microbial attack [4]. Hydrocarbons are hazardous to plants and animals, are also known to be carcinogenic, mutagenic and potent immuno-toxicants posing a serious threat to human and animal health [4]. Thus incorporation of hydrocarbons in natural environment is not desirable, makes its treatment and proper disposal inevitable. Various important processes influence the fate of hydrocarbons in nature, like sorption, volatilization, a biotic transformation (chemical or photochemical), and biotransformation. Since microorganisms play an important role in biogeochemical cycles, the biotransformation is of major concern. The other method mentioned either just fixes or transports the contaminants or is not very effective in nature [2]. Biotransformation is a natural process, which can be used to solve environmental issues, the process then known as Bioremediation.

\section{Bioremediation and organisms degrading hydrocarbons}

Bioremediation can be defined as the use of living organisms to detoxify or remove pollutants owing to their diverse metabolic capabilities. The process is considered as non-invasive and cost effective which makes it favorable to practice. [4]. Bioremediation is carried out by living forms. Among others, microorganisms are also involved in biologically degrading complex matter into simpler fragments, which renders it harmless and also makes it available to other organisms for their consumption. Bioremediation is achieved by existing metabolic potential of indigenous microorganisms or by introducing microorganisms through selection on basis of their catabolic activities or even by introduction of genetically enhanced microorganisms which are incorporated with such functions [1]. Its effectiveness depends on the extent to which the microbial population or consortium can be enriched and maintained in environment, when few or no indigenous degradative microorganisms exists in the contaminated area. Hydrocarbons are insoluble in water, thus in order to consume hydrocarbon derivatives, microorganisms need to emulsify it first in the solution or medium. For this, they are known to produce surface active agents i.e., biosurfactants, 
thus rendering the hydrocarbons susceptible to biodegradation [5].

\section{Microbial community}

Various microorganisms have hydrocarbon degradative potential. They consume hydrocarbons either individually or in consortia. Many aerobic bacterial genus viz., Pseudomonas, Mycobacterium, Rodococcus, Arthobacter, Acinetobacter, Nocardia and Bacillus are known for their degradative properties. Some fungi also have the ability to degrade hydrocarbon based pollutants like Planerochaete chrysosporium (White rot fungus) is an example of ligninolytic fungi capable of degrading polyaromatic hydrocarbons and other harmful environmental pollutants. Cunninghamella echinulata and Mycorrhizal fungi have also been used for the remediation of PHC-polluted soil [6].

\section{Effective microbial consortium}

The advantages of employing mixed cultures as opposed to pure cultures in bioremediation have been well documented. The degradative capacity of any microbial consortium is not necessarily the result of merely adding together of the capacities of the individual strains forming the association. It could be attributed to the effects of synergistic interactions among members of the association [7].

\section{Mutagenesis to enhance degradation}

Newly arisen mutations can have very different impacts on the fitness of the organism, ranging from deleterious through neutral to beneficial. However, they appear at very different rates [8]. There are various ways to induce mutation. One such method is use of UV radiation. UV mutagenesis has also come up as a tool, to enhance degradation by indigenous bacteria [9]. Indigenous microorganisms play a major role in bioremediation, as they are adapted to the extremities of the polluted site. They are able to consume the pollutant as substrate and convert it to simpler forms which are safe to handle by the environment. Studying the characteristics of the polluted site and physiology of the indigenous microbes can thus help to develop a relation between the two; thus can give better understanding and insight on the bioremediation processes. The phylogenetic study helps one to infer the interrelationship between organisms. Thus phylogenetic study of such indigenous microbes can help us understand the relation between them better. And this can also help us to infer the synergistic relationship that may prevail between them to carry out the degradation process. The purpose of the study is to collect the sample from hydrocarbon contaminated site, to identify microbial communities and prepare microbial indices and to determine relationship between physiological study in community development.

\section{Materials and Methods}

\section{Sample collection}

Hydrocarbon based polluted samples were collected from industrial area located near south Gujarat (Figure 1).

\section{Physico-chemical \& organic analysis of the sample}

The collected samples were scrutinized for their physicchemical \& organic properties according to the standard prescribed methods [10].

Enrichment: The samples were then enriched by suspending in Mineral Salt Medium (MSM).

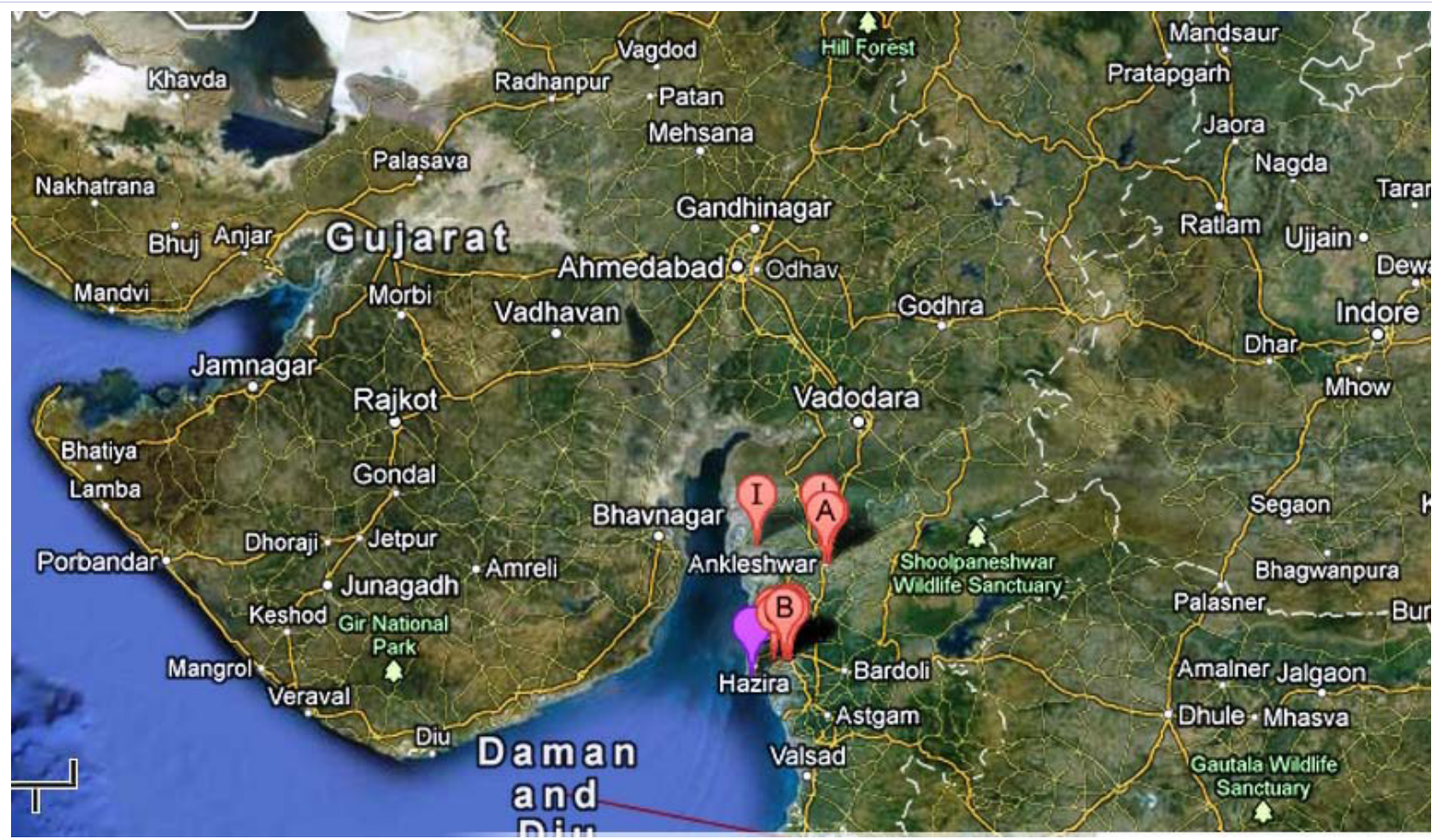

Figure 1: Showing Industrial area in South Gujarat region from where sample has been collected. (Courtesy: Google earth). 
Microbial analysis: The samples after enrichment was scrutinised further by inoculating in different mediums: Mineral Salt Medium (MSM) and Tributyrin Agar medium (TBA); in addition to petroleum derivatives so as to culture only hydrocarbon degrading microbes [11]. Thus a synthetic medium was formulated using hydrocarbon based substrate i.e., petroleum derivatives along with the hydrocarbon extracted from the collected sample. Tributyrin Agar showed colonies development within 48 hours as compared to more than 72 hours in the former, thus TBA was used further in the study.

Tests for hydrocarbon degrading activity: Series of preliminary tests were carried out to check the hydrocarbon degrading capacity of the isolates, viz., drop collapse test, oil spread method, Blue plate agar, Haemolytic activity was checked using blood agar and then confirmatory test-Phenol sulphuric acid test [12].

Effects of various factors on degradation: Various factors like temperature, $\mathrm{pH}$, nitrogen sources and substrate sources and concentration were tested for their effect on degradation rate.

Effective microbial consortium: Microbial consortium was formulated from the isolates, to evaluate the degradation properties of individual isolates as compared to different consortium so formulated.

Mutagenesis: Induced mutation was carried out by exposing 24 hours old culture to UV radiation for 30 mins. The degradation carried out by mutated strain was compared to that of carried out by wild type strain [9].

\section{Result and Discussion}

\section{Analysis of samples}

Sample collected from polluted sites were characterized for their physical, chemical and organic properties. The results obtained are as mentioned in the tables below (Table 1; Figure $2(a, b, c, d, e))$.

These samples were suspended in MSM media, as mentioned above for enrichment of indigenous microorganisms. Figure 3 shows the enrichment flasks.

Then the medium was streaked on MSM and TBA, with petrol spread on top so as to grow only hydrocarbon consuming colonies. In table $2 \& 3$, the results of microbial community count and calculation of microbial diversity Indices is shown.

Only bacterial community was observed in the sample, no fungal or actinomycete growth was observed throughout the study. Bacterial colonies so formed were checked for varies characteristics, viz., Gram's reaction, motility, Capsule formation and so on. 11 isolates were obtained and were studied further. The results are mentioned in the table 4.

\section{Morphological characterization of isolates}

Out of 11 above mentioned isolates, 8 isolates viz. A,B,C,D,F,G,H \& K were found to be Gram Negative. The remaining three isolates; E, I\& J were found to be gram variable. Their microscopic study showed that all of the isolates were short rods. The isolates were checked for capsule formation by carrying out capsule staining method: Maneval's method of capsule staining. It was found that isolates were non- capsulated. Motility was checked by standard method, which indicated that all isolates were motile.

\section{Oil spreading assay}

This method was developed by Morikawa. It is based on the oil displacement activity [12]. All the isolates were assessed by this method. But none of the isolates gave positive result.

\section{Drop collapse method}

This assay relies on the destabilization of liquids by secondary metabolites produced by hydrocarbon consuming microorganisms, i.e., Biosurfactants [12]. None of the isolates gave positive result in this method.

\section{Blue agar plate}

This method was developed by [13]. The microbes of interest are inoculated on a light blue mineral salt agar plate containing cationic surfactant Cetyl-Trimethyl-Ammonium Bromide (CTAB) and the basic dye methylene blue. If microbes are able to degrade hydrocarbons, they secret anionic surfactants which form a dark blue, insoluble ion pair with cetyl-trimethyl-ammonium bromide and methylene blue. The positive isolates will thus form dark blue coloured colonies [12]. Isolates A, C, D, F, G \& H gave positive results in this test. Other colonies showed negative results (Figure 4).

\section{Blood agar haemolysis}

This method was developed by [14]; and is based on the fact that hydrocarbon degrading microbes are able to haemolyse the red blood; observe for zone of hemolysis [12]. Isolates A, C, D, F \& G showed zone of hemolysis (Figure 5; Table 5).

\section{Confirmatory test}

Phenol- sulphuric acid test: The positive isolates were further scrutinized by confirmatory test [12] (Figure 6). Only positive results are shown here. Isolates $\mathrm{A}, \mathrm{C}, \mathrm{D}, \mathrm{F} \& \mathrm{G}$ showed positive results in this test. Isolate $\mathrm{H}$ gave positive result only with blue agar plate; still it was checked further for the hydrocarbon degrading property.

Table 1: Result of physical analysis of sample.

\begin{tabular}{|l|l|l|l|l|}
\hline Parameters & Sample-A & Sample-B & Sample-C \\
\hline Physical state & Viscous Liquid & Viscous Liquid & Viscous Liquid \\
\hline Appearance & Dark Brown & Dark Brown & Dark Brown \\
\hline Flammability & Flammable & Flammable & Slight Flammable \\
\hline
\end{tabular}




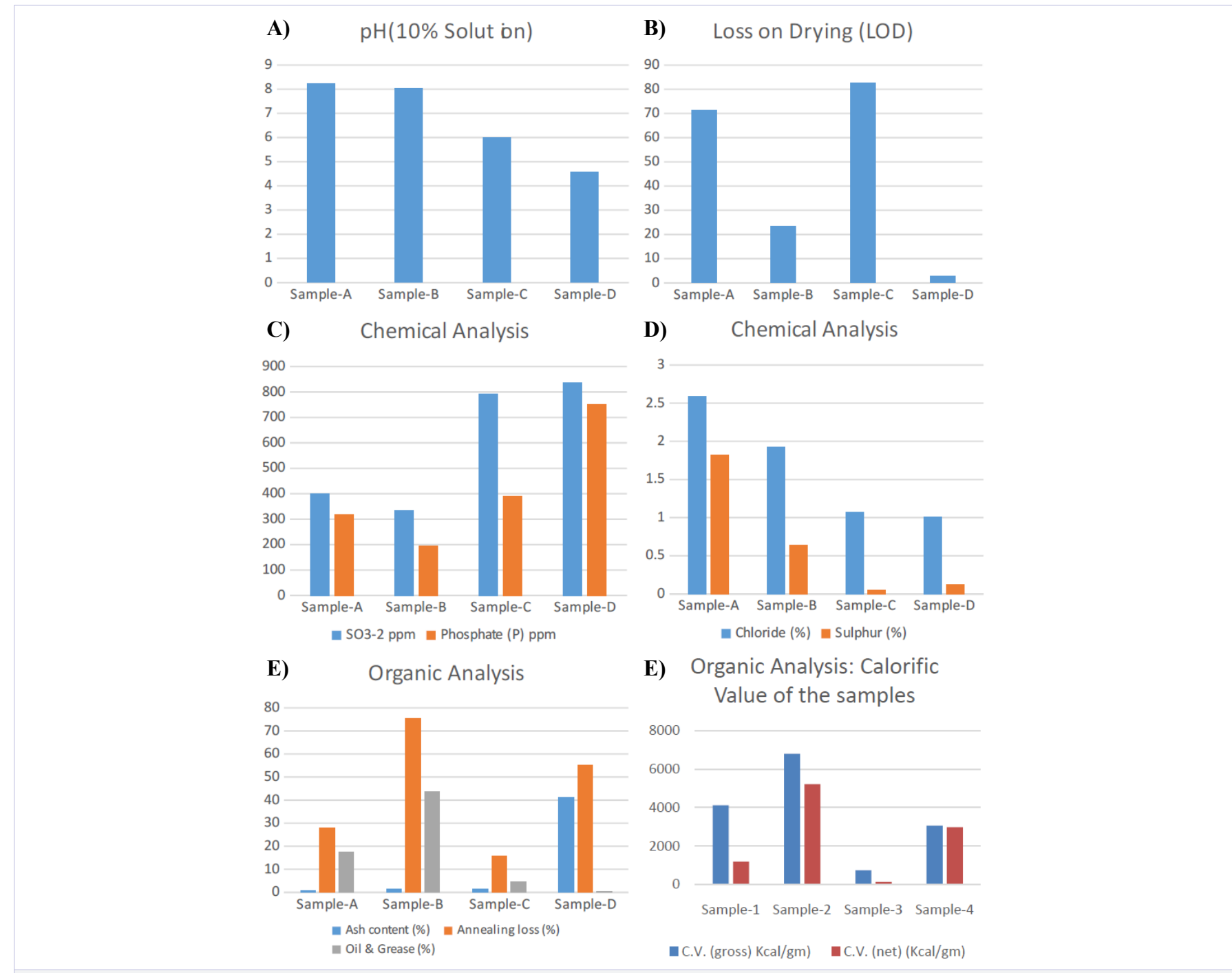

Figure 2: Results of Physical, chemical and organic analysis of sample. a: Physical Analysis : $\mathrm{pH}$ (10\% Solution). b: Physical Analysis: Loss on Drying. c: Chem. Analysis: SO3-2 and Phosphate (P). d: Chem. Analysis: Chloride (\%) \& Sulphur (\%). Org. Analysis: Ash content (\%), Annealing loss (\%) and Oil \& grease (\%). f: Org. Analysis: Calorific Values Gross and net (Kcal/ gm).

Table 2: Microbial Community.

\begin{tabular}{|c|c|c|}
\hline Sample & Bacteria (CFU/ml) & Colonies \\
\hline A & $1.2 \times 10^{5}$ & 3 \\
\hline B & $1.1 \times 10^{5}$ & 2 \\
\hline C & $1.1 \times 10^{5}$ & 2 \\
\hline D & $1.3 \times 10^{5}$ & 4 \\
\hline
\end{tabular}

Table 3: Microbial diversity Indices (Using Past-3 Software).

\begin{tabular}{|l|l|}
\hline Index & Bacterial diversity \\
\hline Taxa_S & 4 \\
\hline Individuals & 4 \\
\hline Dominance_D & 0.2512 \\
\hline Simpson_1-D & 0.7488 \\
\hline Shannon_H & 1.384 \\
\hline
\end{tabular}

\begin{tabular}{|l|l|}
\hline Evenness_e $^{\wedge} \mathrm{H} / \mathrm{S}$ & 0.9975 \\
\hline Brillouin & 0.6034 \\
\hline Menhinick & 1.845 \\
\hline Margalef & 2.164 \\
\hline Equitability_J & 0.9982 \\
\hline Fisher_alpha & 12.73 \\
\hline Berger-Parker & 0.2128 \\
\hline Chao-1 & 4 \\
\hline
\end{tabular}

\section{Results of effects of various factors on degradation Nitrogen Sources}

The effect of different nitrogen sources on the degradation capacity was also studied. The nitrogen sources taken into consideration were peptone, Sodium Nitrate $\left(\mathrm{NaNO}_{3}\right)$, potassium 

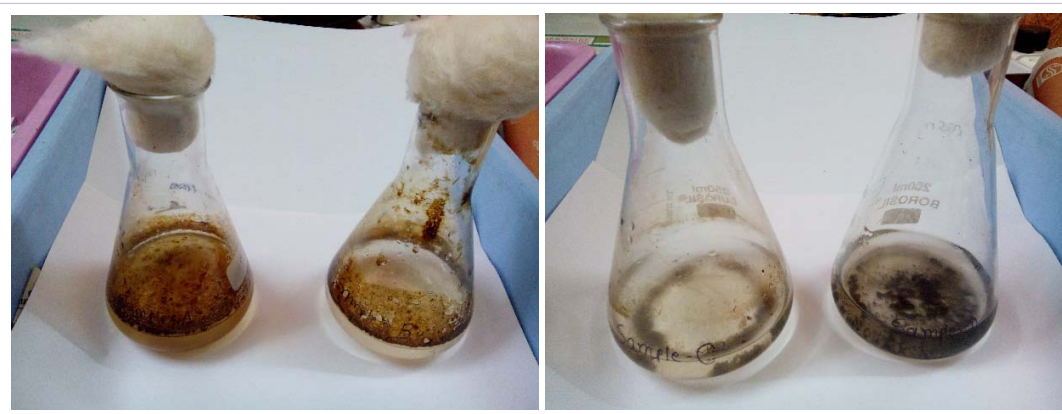

Figure 3: Samples A, B, C \& D suspended in MSM media.

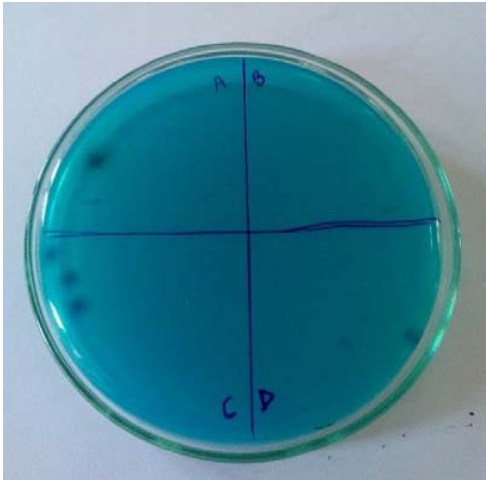

Figure 4: Blue Agar Plate.

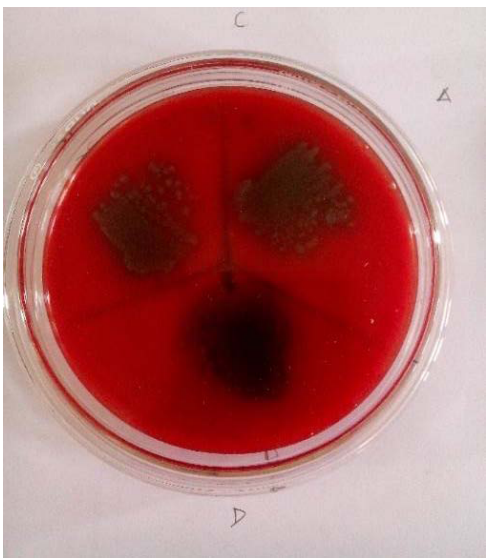

Figure 5: Blood Agar Plate.

Nitrate $\left(\mathrm{KNO}_{3}\right)$, Calcium Nitrate Tetra Hydrate $\left(\mathrm{Ca}\left(\mathrm{NO}_{3}\right)_{2} \cdot 4 \mathrm{H}_{2} \mathrm{O}\right)$, Ammonium Sulphate $\left(\mathrm{NH}_{4} \mathrm{SO}_{4}\right)$, Ammonium Chloride $\left(\mathrm{NH}_{4} \mathrm{Cl}\right)$ and $\mathrm{NH}_{4} \mathrm{NO}_{3}$ ). Among these, peptone gave better results (Figure 7a). Here a too exceptionally high result with isolate $\mathrm{G}$ was observed with Ammonium Sulphate was due to pigment formation.

\section{Different substrate concentration}

A synthetic medium was prepared by using petroleum derivatives. The concentration and type of petroleum derivative is varied to study its effect on the growth and degradative properties with varying substrates Figure $7 \mathrm{~b}$ to $7 \mathrm{~g}$. shows results of different concentration of petrol, kerosene, diesel and combinations of these petroleum derivatives at different concentration.

\section{Degradation by formulated consortium}

Formulated consortium was studied for their degradative properties, and the result of the same are as shown in figure $7 \mathrm{~h} \&$ figure $7 \mathrm{i}$. In Figure $7 \mathrm{~h}$, OD of consortium formulated by combination of two isolates: Consortium I and by combination of three isolates: Consortium II. The relative population size of the isolates for these consortiums were kept equal i.e., in 1:1 ratio. The results of consortium I as been shown in Figure $7 \mathrm{~h}$; combination of $\mathrm{CF}$ and CG gave highest OD among others. And in figure 7i, OD of combination of Consortium II has been shown. Among which ACF showed maximum OD i.e., 0.4, which is higher than CF \& CG as well which is nearly 0.25 (Figure 8).

\section{Enhancing degradative property by mutation}

The hydrocarbon degrading property of isolates was seen to be improved when isolates were mutated by UV radiation. The figure below shows that mutation enhanced the degradative properties of the isolates as compared to that of wild type strains (Figure 9).

\section{Identification of microorganisms}

Isolated microorganisms has been identified by 16s RNA gene sequencing (Saffron's Gene Laboratory) and further submitted to NCBI. The submitted sequences got accession numbers as below (Table 6):

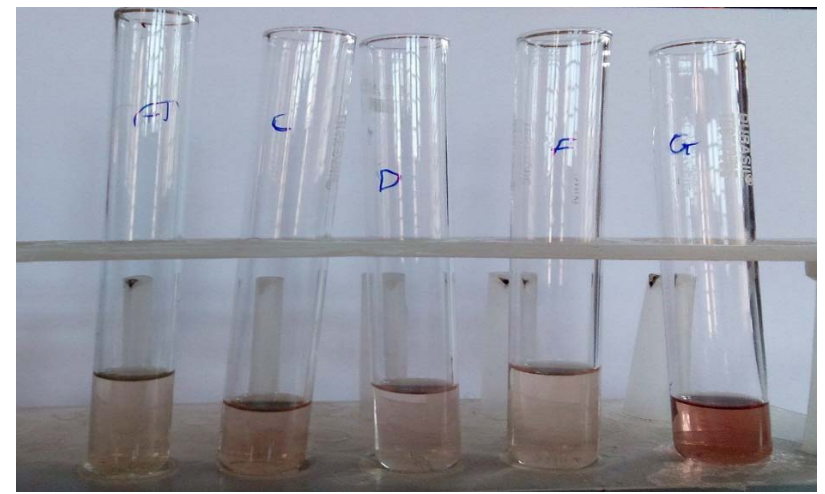

Figure 6: Phenol - Sulphuric Acid test (Confirmatory test). 


\begin{tabular}{|c|c|c|c|c|c|c|c|c|}
\hline Isolate & $\begin{array}{l}\text { Gram's } \\
\text { Reaction }\end{array}$ & $\begin{array}{l}\text { Capsule } \\
\text { formation }\end{array}$ & Motility & $\begin{array}{l}\text { Oil Spreading } \\
\text { Assay }\end{array}$ & $\begin{array}{l}\text { Drop } \\
\text { Collapse }\end{array}$ & $\begin{array}{l}\text { Blue } \\
\text { Agar } \\
\text { Plate }\end{array}$ & $\begin{array}{l}\text { Haemolytic } \\
\text { reaction }\end{array}$ & $\begin{array}{l}\text { Confirmatory test } \\
\text { (Phenol- Sulphuric Acid test) }\end{array}$ \\
\hline A & Negative & No & Yes & No & No & Yes & Yes: $ß$ & Yes \\
\hline B & Negative & No & Yes & No & No & No & No & No \\
\hline $\mathrm{C}$ & Negative & No & Yes & No & No & Yes & Yes: $ß$ & Yes \\
\hline D & Negative & No & Yes & No & No & Yes & Yes: $ß$ & Yes \\
\hline $\mathrm{E}$ & Variable & No & Yes & No & No & No & No & No \\
\hline $\mathrm{F}$ & Negative & No & Yes & No & No & Yes & Yes : $ß$ & Yes \\
\hline G & Negative & No & Yes & No & No & Yes & Yes: ß & Yes \\
\hline $\mathrm{H}$ & Negative & No & Yes & No & No & Yes & No & No \\
\hline I & Variable & No & No & No & No & No & No & No \\
\hline J & Variable & No & No & No & No & No & No & No \\
\hline K & Negative & No & No & No & No & No & No & No \\
\hline
\end{tabular}

Table 5: Diameter of zone of haemolysis.

\begin{tabular}{|l|l|l|l|l|l|}
\hline Colony & Isolate $\mathbf{A}$ & Isolate C & Isolate D & Isolate $\mathbf{F}$ & Isolate G \\
\hline Zone diameter & $1 \mathrm{~mm}$ & $2 \mathrm{~mm}$ & $2 \mathrm{~mm}$ & $1 \mathrm{~mm}$ & $1 \mathrm{~mm}$ \\
\hline
\end{tabular}

\begin{tabular}{|l|l|l|l|}
\hline Table 6: & \multicolumn{3}{|l|}{} \\
\hline Sample & Isolate & Strain & Accession number \\
\hline A & Isolate A & Pseudomonas aeruginosa strain RRLP1 & KU314415 \\
\hline & Isolate G & Pseudomonas aeruginosa RRLP1 & KU314419 \\
\hline B & Isolate C & Pseudomonas aeruginosa Strain AS-1 & KU314416 \\
\hline C & Isolate H & Pseudomonas aeruginosa Strain JQ-41 & KU314420 \\
\hline D & Isolate D & Pseudomonas aeruginosa Strain SI5(1)3 & KU314417 \\
\hline
\end{tabular}

\section{Phylogenetic study}

Phylogram was prepared in MEGA 7 software Figure 10.

\section{Conclusion}

The samples extracted from the hydrocarbon based waste matter showed majorly Gram negative to gram variable microorganisms. Out of eleven, six Pseudomonas species were isolated with Hydrocarbon degrading properties. These dominated Pseudomonas species were identified by 16s RNA sequence analysis. The Pseudomonas species identified are Isolate A: Pseudomonas aeruginosa strain RRLP1, Isolate C: Pseudomonas aeruginosa Strain AS-1, Isolate D: Pseudomonas aeruginosa Strain SI5 (1)3, Isolate F: Pseudomonas spp. Strain 14-1, Isolate G: Pseudomonas aeruginosa RRLP1, Isolate H: Pseudomonas aeruginosa Strain JQ-41. On assessing effects of various parameters on their hydrocarbon degradation properties, it was found that at the isolates were able to grow under various physical conditions since their origin physical condition was also extreme. It was observed that, at temperature $30^{\circ} \mathrm{C}$, consistent growth was observed as compared to $37^{\circ} \mathrm{C}$, which showed varied growth response. When isolates were exposed to varied $\mathrm{pH}$ values, they gave growth in $\mathrm{pH}$ range of 4.5 to $\mathrm{pH} 9.0$. However, at $\mathrm{pH} 4$ no growth was observed with any isolate and at $\mathrm{pH} 9$, comparatively less growth was observed considering lesser OD values. Consistent growth was seen in $\mathrm{pH}$ range of 5.5 to 6.5. It was also observed that isolates were able to grow in different $\mathrm{N}$ sources but among those, peptone gave consistent results. And in carbon concentration, petrol $0.005 \%$ gave consistently good growth than Kerosene and diesel at different concentrations. High growth among the isolates was observed by isolate D: Pseudomonas aeruginosa Strain SI5(1)3, at petrol concentration of $0.005 \%(\mathrm{v} / \mathrm{v})$, with peptone as Nitrogen source, with $\mathrm{pH}$ of 6.0 , when incubated at temperature $30^{\circ} \mathrm{C}$ for 72 hours. And isolate F: Pseudomonas spp. Strain 14-1 was able to show pigmentation in different physical conditions which was not observed in any other isolate. The study represented that Pseudomonas species isolated from hydrocarbon contaminated waste matter were able to degrade various petroleum derivatives at different concentration and also under the influence of various physical conditions. Moreover different strains of Pseudomonas should be further studied for their hydrocarbon degradative properties at large scale. This work can be helpful to design consortia to biodegrade hydrocarbon pollution in natural environment and to have more insight in this area of research which needs more attention considering the prevailing pollution rate. 
A) Effect of different $\mathrm{N}$ source

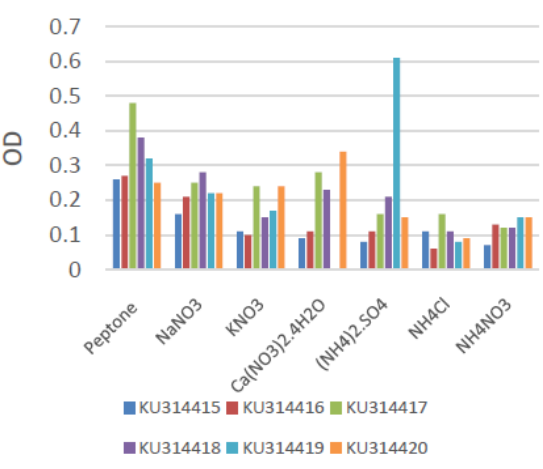

D) Effect of different Diesel conc.

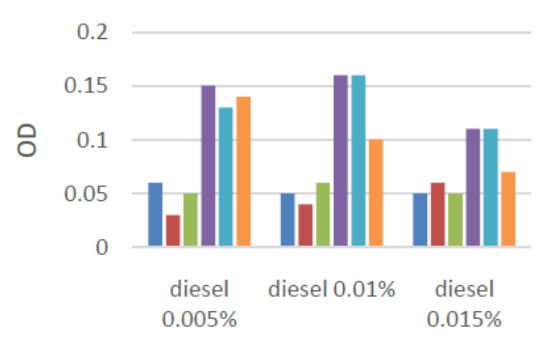

- KU314415 = KU314416 = KU314417

— KU314418 = KU314419 — KU314420

G) Effect of Diesel+Kerosene in different conc.

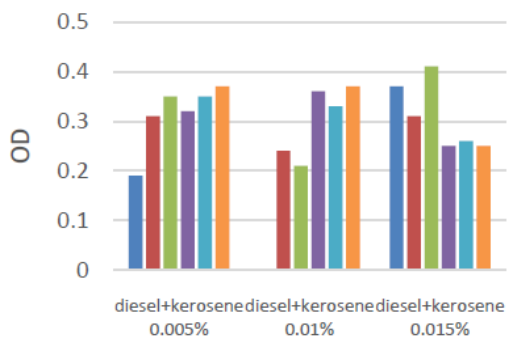

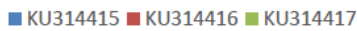

— KU314418 — KU314419 " KU314420

I)

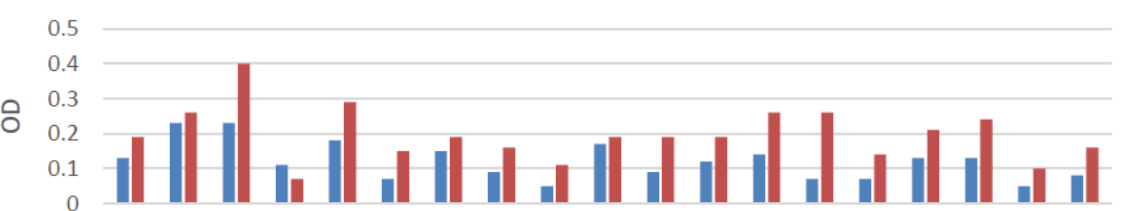

ACD ACG ACF ACH ADF ADH AFG AGH AFH ADG CDF CDG CDH CFG CFH CGH DFG DFH FGH
B) Effect of different Petrol conc.

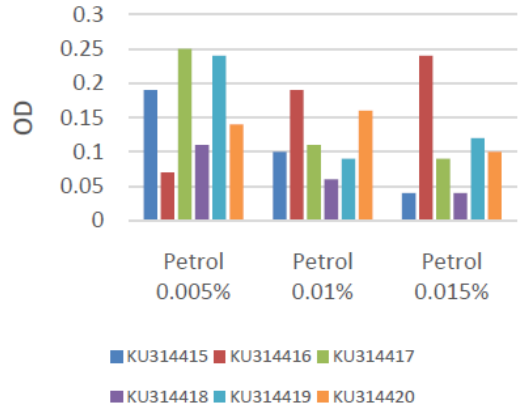

E) Effect of Petrol+Diesel in different conc.

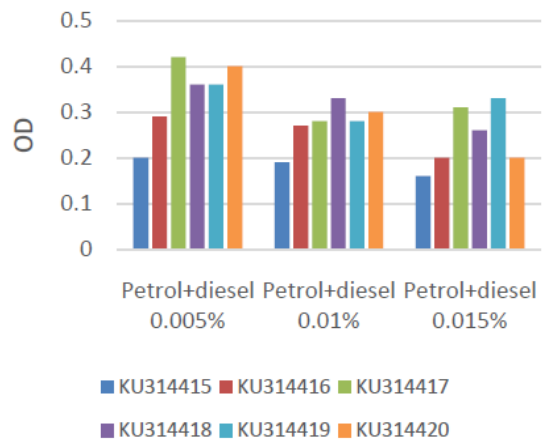

H)

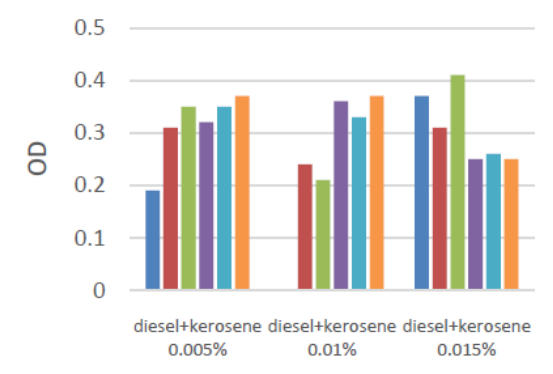

— KU314415 — KU314416 = KU314417

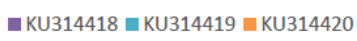

C) Effect of different Kerosene conc.

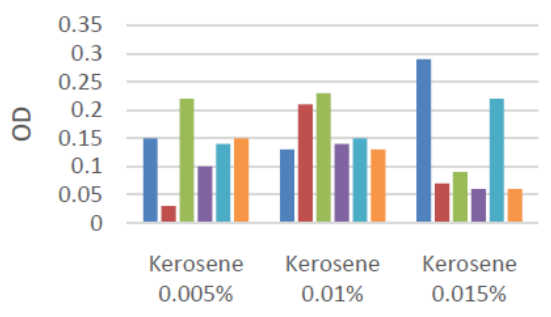

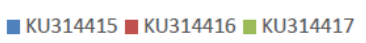
" KU314418 ㄸ KU314419 ㄸ KU314420

F) Effect of Petrol+Kerosene in different conc.

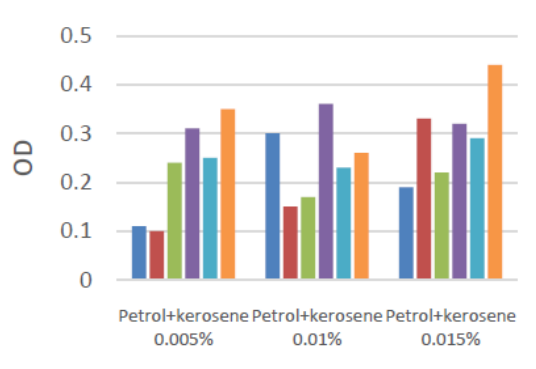

— KU314415 — KU314416 = KU314417 - KU314418 = KU314419 = KU314420

-DAY 3 DAY 5

Figure 7: Results of effects of different parameters ( $\mathbf{a}, \mathbf{c}, \mathbf{d}, \mathbf{f}, \mathbf{g}, \mathbf{h}$ and $\mathbf{i}$ are the isolates as mentioned below). $\mathrm{a}$ : Effect of different Nitrogen (N) source. b: Effect of different Petrol concentration. c: Effect of Different Kerosene Concentration. d: Effect of Different Diesel Concentration. e: Effect of Petrol+Diesel in different conc. f: Effect of Petrol+Kerosene in different conc. g: Effect of Diesel+kerosene different conc. h: Degradation by consortium prepared by combining two isolates. i: Degradation by consortium prepared by combining three isolates. 


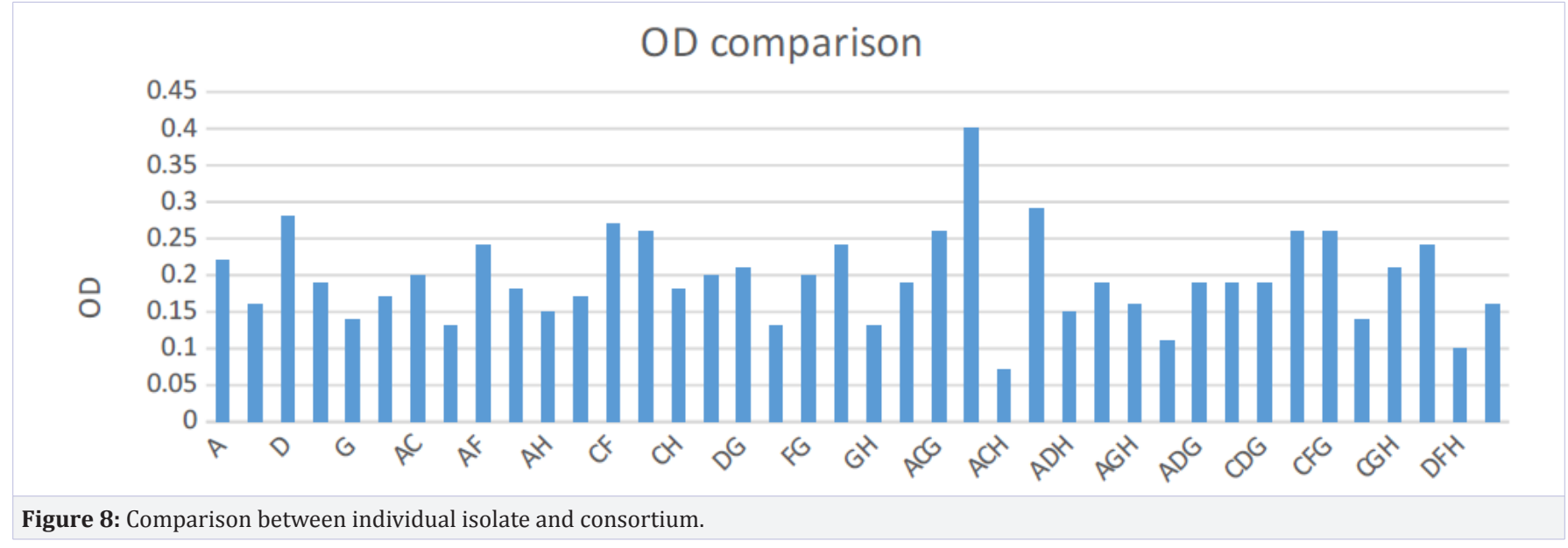

Figure 8: Comparison between individual isolate and consortium.

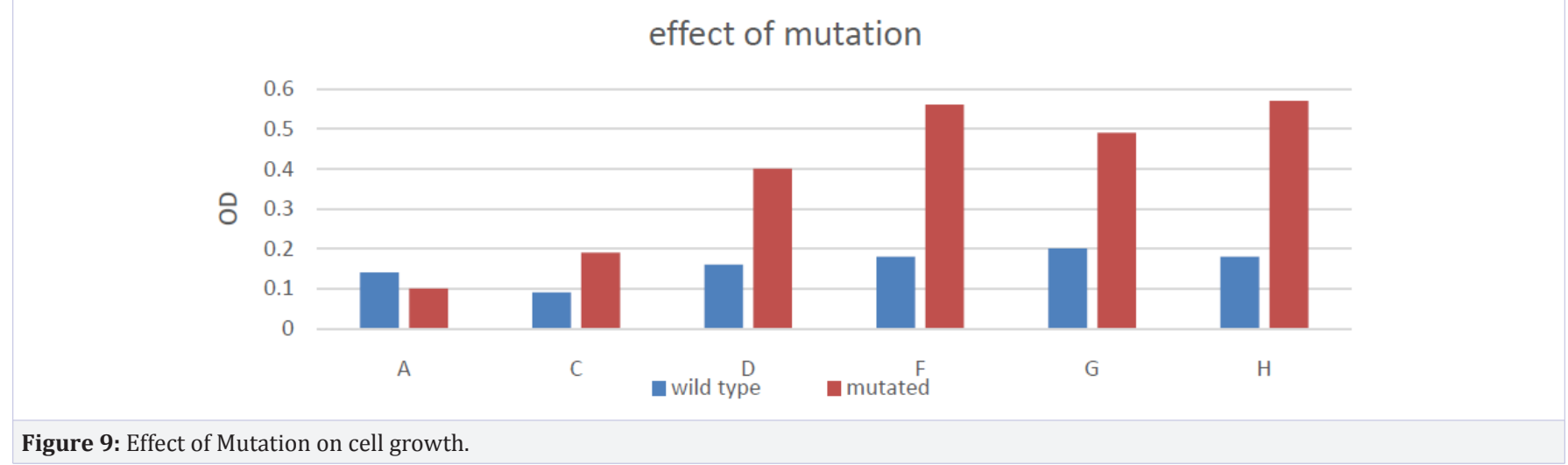

Figure 9: Effect of Mutation on cell growth.

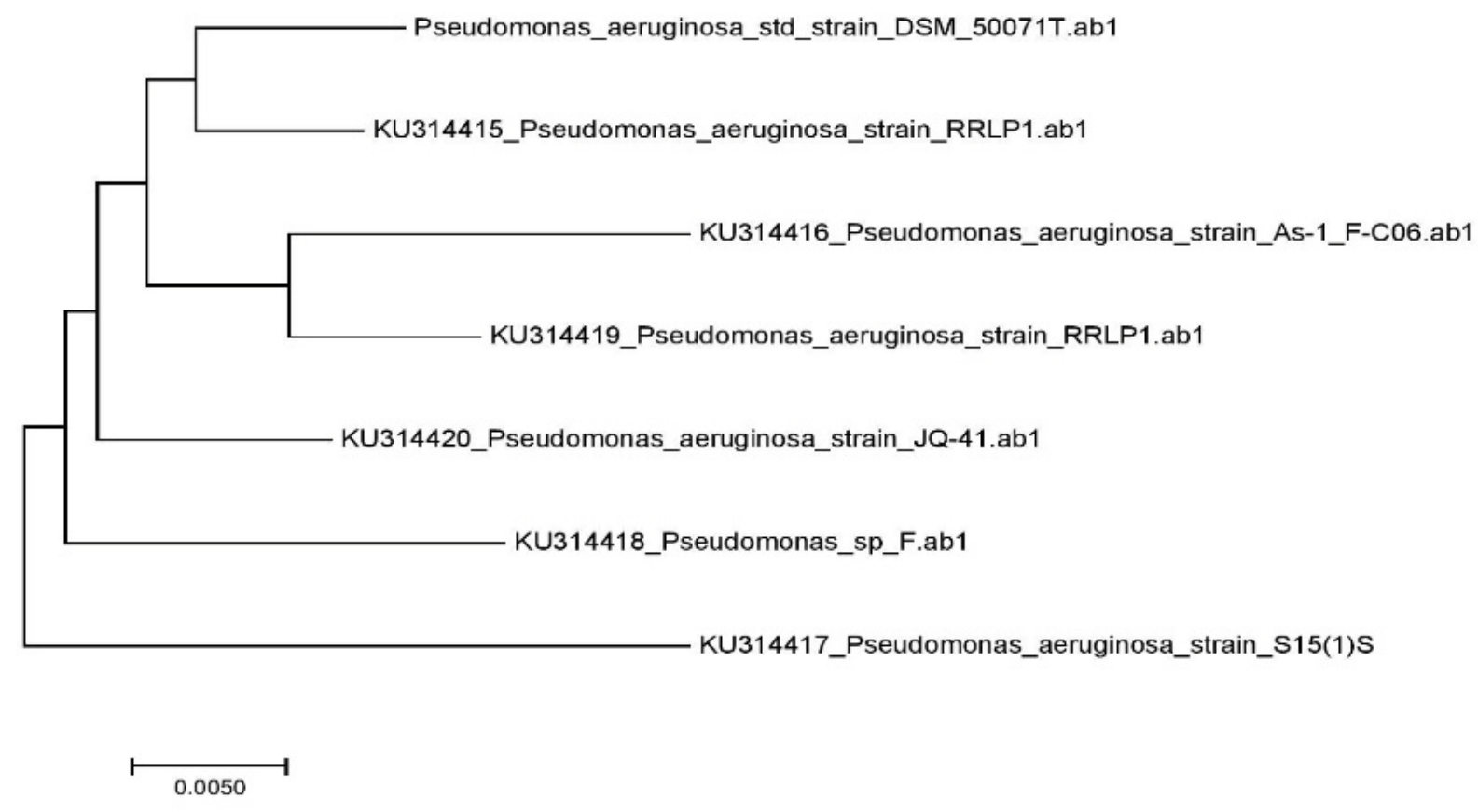

Figure 10: Phylogram of the isolates.

Citation: Mandalaywala HP, Trivedi R (2016) Effective Microbial Consortium of Bacteria Isolated from Hydrocarbon Polluted Soils of Gujarat, India. J Adv Res Biotech 1(1): 9. DOI: http://dx.doi.org/ 10.15226/2475-4714/1/1/00106 


\section{References}

1. Ilyina A, Castillo S, Villarreal S, Ramirez E, et al. Isolation of soil bacteria for bioremediation of hydrocarbon contamination. вестн. Моск. Ун-та. 2003:44(1):88-91.

2. Peixoto RS, Vermelho AB, Rosado AS. Petroleum-Degrading Enzymes: Bioremediation and New Prospects. Enzyme Res. 2011;2011:475193. Doi: 10.4061/2011/475193.

3. Oliveira I. et al. Microbial Hydrocarbon Degradation: Efforts to Understand Biodegradation in Petroleum Reservoirs. DOI: $10.5772 / 55920$.

4. Das N, Chandran P. Microbial Degradation of Petroleum Hydrocarbon Contaminants: An Overview. Biotechnol Res Int. 2011;2011:941810. Doi: $10.4061 / 2011 / 941810$.

5. Panda SKKRN, Panda CR. Isolation and identification of petroleum hydrocarbon degrading microorganisms from oil contaminated environment. Int J Environ Sci (IJEST). 2013;3(5):1314-1324. doi:10.6088/ijes.2013030500001.

6. Chibuike, GU, Obiora, SC. Bioremediation of hydrocarbonpolluted soils for improved crop performance. Int J Environ Sci (IJEST).2014;4(5):840-858. Doi: 10.6088/ijes.2014040404524.

7. Farinazleen MG, Raja Noor ZAR, Abu Bakar S, Mahiran B. Biodegradation of hydrocarbons in soil by microbial consortium. Int Biodeterior Biodegradation.2004;54(1):61-67. Doi:10.1016/j. ibiod.2004.02.002.
8. Denamur E, Matic I. Evolution of mutation rates in bacteria MolMicrobiol.2006;60(4):820-7. Doi:10.1111/j.

9. Naveenkumar SMN, Ganesan S, Manivannan SP, Velsamy G. Isolation, Screening and In Vitro Mutational Assessment of Indigenous Soil Bacteria for Enhanced Capability in Petroleum Degradation. Int J Environ Sci (IJEST) 2010;1(4):493-518.

10.APHA, AAWI. Standard Methods for the Examination of Water and Wastewater. In: Eugene W. Rice, Laura Bridgewater. 22nd Edition. 2012.

11. Anupam Mittal, Padma Singh. Isolation of hydrocarbon degrading bacteria from soils contaminated with crude oil spills. Indian J Exp Biol. 2009;47(9):760-5.

12. Rehman Naziya NMA, SMB, Dixit PP and Deshmukh AM. Screening Of Biosurfactant Producing Microorganisms from Oil Contaminated Soils of Osmanabad Region, Maharashtra, India. International Science Journal. 2014;1(1):35-39.

13. Inka Siegmund and Fritz Wagner. New method for detecting rhamnolipids excreted by Pseudomonas species during growth on mineral agar. Biotechnology Techniques. 1991;5(4):265-268. Doi: 10.1007/BF02438660.

14. Catherine NM, Terry YK. Chow, Bernard F. Gibbs. Enhanced biosurfactant production by a mutant Bacillus subtilis strain Applied Microbiology and Biotechnology. 1989;31(5):486-489. Doi: 10.1007/ BF00270781. 